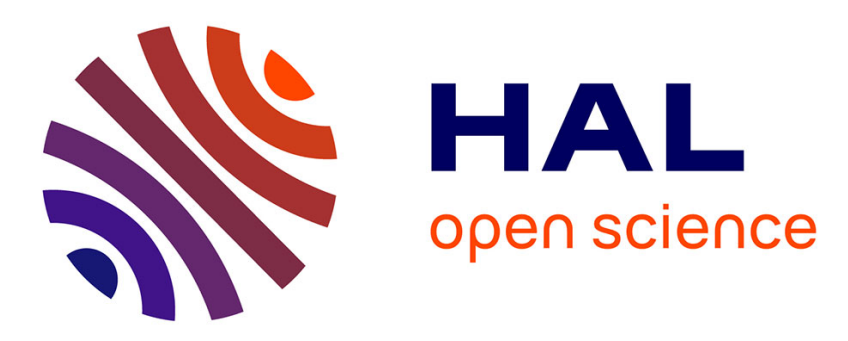

\title{
Correlation Between Thermoelectric Power (TEP) and Martensite Start Temperature (Ms) Measurements of 9Cr-W-V-(Ta) Martensitic Steels
}

\author{
J. Brachet
}

\section{- To cite this version:}

J. Brachet. Correlation Between Thermoelectric Power (TEP) and Martensite Start Temperature (Ms) Measurements of 9Cr-W-V-(Ta) Martensitic Steels. Journal de Physique IV Proceedings, 1995, 05 (C8), pp.C8-339-C8-344. 10.1051/jp4:1995849 . jpa-00254098

\section{HAL Id: jpa-00254098 https://hal.science/jpa-00254098}

Submitted on 1 Jan 1995

HAL is a multi-disciplinary open access archive for the deposit and dissemination of scientific research documents, whether they are published or not. The documents may come from teaching and research institutions in France or abroad, or from public or private research centers.
L'archive ouverte pluridisciplinaire HAL, est destinée au dépôt et à la diffusion de documents scientifiques de niveau recherche, publiés ou non, émanant des établissements d'enseignement et de recherche français ou étrangers, des laboratoires publics ou privés. 


\title{
Correlation Between Thermoelectric Power (TEP) and Martensite Start Temperature (Ms) Measurements of $9 \mathrm{Cr}-\mathrm{W}-\mathrm{V}-(\mathrm{Ta})$ Martensitic Steels
}

\author{
J.C. Brachet \\ Commissariat à l'Energie Atomique, DTA/CEREM/DECM/SRMA, C.E. Saclay, 91191 Gif-sur-Yvette \\ cedex, France
}

\begin{abstract}
Low Activation Martensitic (9Cr-W-V,Ta) steels are studied for Fusion reactor applications. This paper deals with the experimental results obtained by using Thermoelectric Power (TEP) technique and Martensite Start (Ms) temperature measurements by dilatometry performed after partial austenite $=>$ ferrite phase transformations of different LAM steels. Six $9-11 \mathrm{Cr} / 0.7-3 \mathrm{~W} / \mathrm{V}, \mathrm{Ta}$ base steels have been studied with different nominal concentrations of interstitial (C+N) elements ranging from 0.1 to 0.2 weight percent. TEP and Ms values have been correlated with the residual interstitial (C+N) concentration in solid solution of the non transformed austenite, which generates martensite during cooling to the ambient temperature. These experimental results seem to evidence that there is a decrease of the $\mathrm{C}$ and $\mathrm{N}$ concentration within the non transformed austenite during both isothermal and anisothermal (i.e. during continuous cooling from the austenite phase field) austenite to ferrite transformations. Some complementary microstructural examinations show that this decrease is associated with a heavy precipitation of chromium rich carbides and/or nitrides during the early stages of the ferrite growth.
\end{abstract}

\section{INTRODUCTION}

Low activation martensitic (LAM) steels of the 9/11CrWVTa type are promising candidates for fusion reactor applications because they exhibit mechanical properties similar to those of commercial martensitic stainless steels of the $9 / 12 \mathrm{Cr}-\mathrm{Mo}(\mathrm{NbV})$ type [1]. For fusion applications, it is necessary to have a good knowledge of the evolution of the microstructure under different thermal cycles, that is the phase transformations and the precipitation reactions that occur under isothermal or anisothermal thermal treatments. These thermal treatments are of technological importance since they can occur during fabrication routes or during weldment operations.

This paper deals with some features of the under-cooling austenite to ferrite and/or martensite phase transformations for both isothermal (TTT) and anisothermal (CCT) conditions. The main results and discussion concern the correlation which has been established between Ms temperature measurements by dilatometry and Thermoelectric Power (TEP) values. This last technique is very sensitive to the fraction of the interstitial ( $\mathrm{C}$ and $\mathrm{N}$ ) atoms in solid solution of a Iron based matrix. BORELLY et al. have established a linear relation between experimental TEP values and residual fractions of $\mathrm{C}$ or $\mathrm{N}$ in solid solution of low alloyed ferritic steels ([2] to [5]). Recently, some TEP measurements have been performed on a conventional 9Cr1Mo martensitic steel [6]. These results seem to evidence that, in this type of steel, TEP technique is also very sensitive to the fraction of interstitial atoms in solid solution. Thus, in this paper, TEP measurements have been made on different "low activation martensitic" (LAM) steels with main alloying elements ranging from : 9 to $11 \% \mathrm{Cr}, 0.7$ to $3 \% \mathrm{~W}, 0.25$ to $0.4 \mathrm{~V}$ and $(\mathrm{C}+\mathrm{N})$ from 0.1 to $0.2 \%$ (weight percents). 


\section{MATERIALS}

Six experimental heats have been produced by AEA-Culham (U.K.). The ingots have been hot rolled and then cold rolled up to $5 \mathrm{~mm}$ thick sheets by CEA-CE2M-LETRAM laboratory. The chemical composition of these steels is shown on table 1.

Table 1 - Chemical composition of LA martensitic steels studied (in wt\%)

\begin{tabular}{|c|c|c|c|c|c|c|c|c|}
\hline Alloy & $\mathrm{C}$ & $\mathrm{Si}$ & $\mathrm{Mn}$ & $\mathrm{Cr}$ & $\mathrm{V}$ & $\mathrm{W}$ & $\mathrm{N}$ & $\mathrm{Ta}$ \\
\hline LA12LC & $\mathbf{0 . 0 9}$ & 0.03 & 1.01 & 9.0 & $\mathbf{0 . 3 8}$ & 0.76 & $\mathbf{0 . 0 3 3}$ & $/$ \\
\hline LA12Ta & $\mathbf{0 . 1 6}$ & 0.03 & 0.80 & $\mathbf{9 . 8}$ & 0.27 & $\mathbf{0 . 8 5}$ & $\mathbf{0 . 0 4 2}$ & $\mathbf{0 . 1 0}$ \\
\hline LA12TaLC & $\mathbf{0 . 0 9}$ & 0.03 & 1.01 & 8.9 & $\mathbf{0 . 3 9}$ & 0.76 & $\mathbf{0 . 0 1 9}$ & $\mathbf{0 . 0 9}$ \\
\hline LA12TaLN & $\mathbf{0 . 1 7}$ & 0.02 & 0.74 & 9.1 & 0.25 & 0.77 & $\mathbf{0 . 0 0 4}$ & $\mathbf{0 . 1 0}$ \\
\hline LA13Ta & $\mathbf{0 . 1 8}$ & 0.04 & 0.70 & 9.0 & 0.25 & $\mathbf{2 . 9 6}$ & $\mathbf{0 . 0 4 5}$ & $\mathbf{0 . 1 1}$ \\
\hline LA4Ta & $\mathbf{0 . 1 4}$ & 0.03 & 0.73 & $\mathbf{1 1 . 2}$ & 0.24 & 0.77 & $\mathbf{0 . 0 4 2}$ & $\mathbf{0 . 0 9}$ \\
\hline
\end{tabular}

From this table it should be noticed that the LA12xx type steels are of great interest because they enable to compare the separate effect of addition of $\mathrm{C}, \mathrm{N}$ and $\mathrm{Ta}$ on a typical base material of the $9 \mathrm{Cr}-$ $0.8 \mathrm{~W}-\mathrm{V}$ type; and this basic composition is close to the "optimum" alloy composition for fusion reactor application [1].

\section{EXPERIMENTAL}

The isothermal and anisothermal phase transformations have been studied by dilatometric techniques. The dilatometric samples have a typical size of $40 \mathrm{~mm}$ in length and $3 \mathrm{~mm}$ in thickness. All samples were first annealed $30 \mathrm{mn}$ at $1050^{\circ} \mathrm{C}$ and then quenched to obtain the same initial metallurgical condition before dilatometric tests.

\section{RESULTS AND DISCUSSION}

\subsection{Phase transformations during cooling :}

The Continuous Cooling Transformation (CCT) diagrams have been established for all the steels studied after austenitization for $30 \mathrm{~min}$. at $1050^{\circ} \mathrm{C}$.

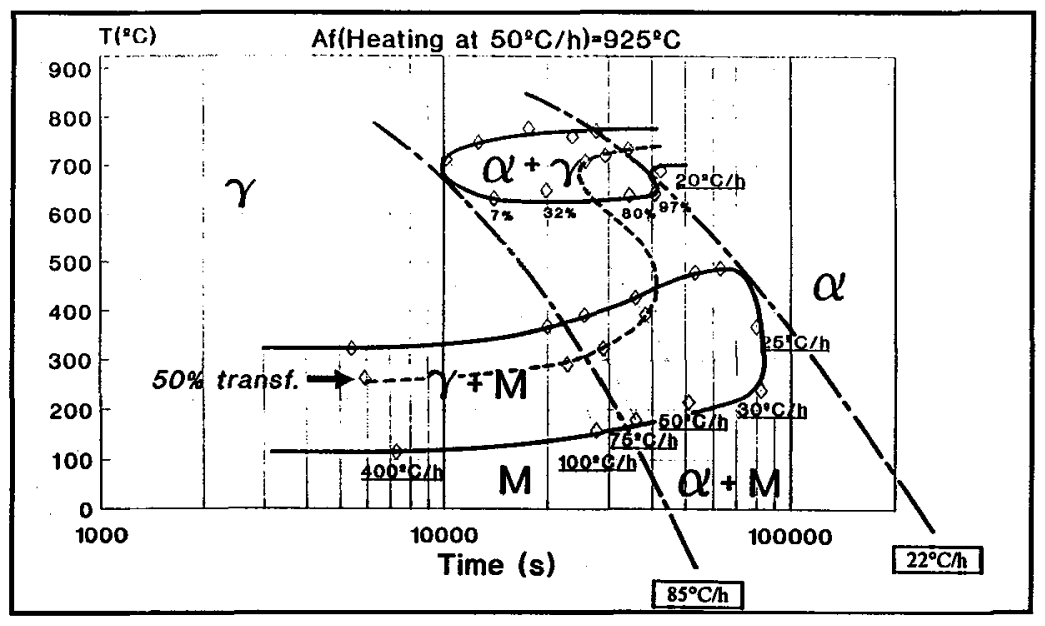

Fig. 1 :CCT diagrams of LA13Ta steel obtained after austenitization for $30 \mathrm{~min}$. at $1050^{\circ} \mathrm{C}$ 
As already observed on conventional $9 \mathrm{Cr}$ 1Mo martensitic steels [7] and as shown on figure 1 for the LA13Ta steel, the CCT diagrams are characterized by two main phase-fields : an extended martensitic field (without noticable precipitation of carbides) and a ferritic field (+ carbides); no intermediate bainitic reactions occur for all the cooling rates tested. The martensitic and ferritic fields are separated by two critical cooling rates, i. e., $\mathbf{R m}$ the minimum rate to obtain a fully transformation of austenite into martensite and $\mathbf{R} \mathbf{f}$ the maximum rate to obtain a fully transformation of austenite into ferrite. Typical $\mathbf{R m}$ values are ranging from 40 to $200^{\circ} \mathrm{C} / \mathrm{h}$. These results indicate that all the steels are fully martensitic after cooling at $400^{\circ} \mathrm{C} / \mathrm{h}$ (furnace cooling).

Figure 2-a shows that for cooling rate values ranging from $R m$ to $R f$ (biphased $\alpha+m$ field), the Ms temperature increases with the decreasing cooling rate and so with the associated increase of ferrite fraction. On the other hand, TEP values decrease with the increase of ferrite fraction as shown on figure 2b. Figure 2-c shows that there is a qualitative linear correlation between experimental Ms and TEP values.

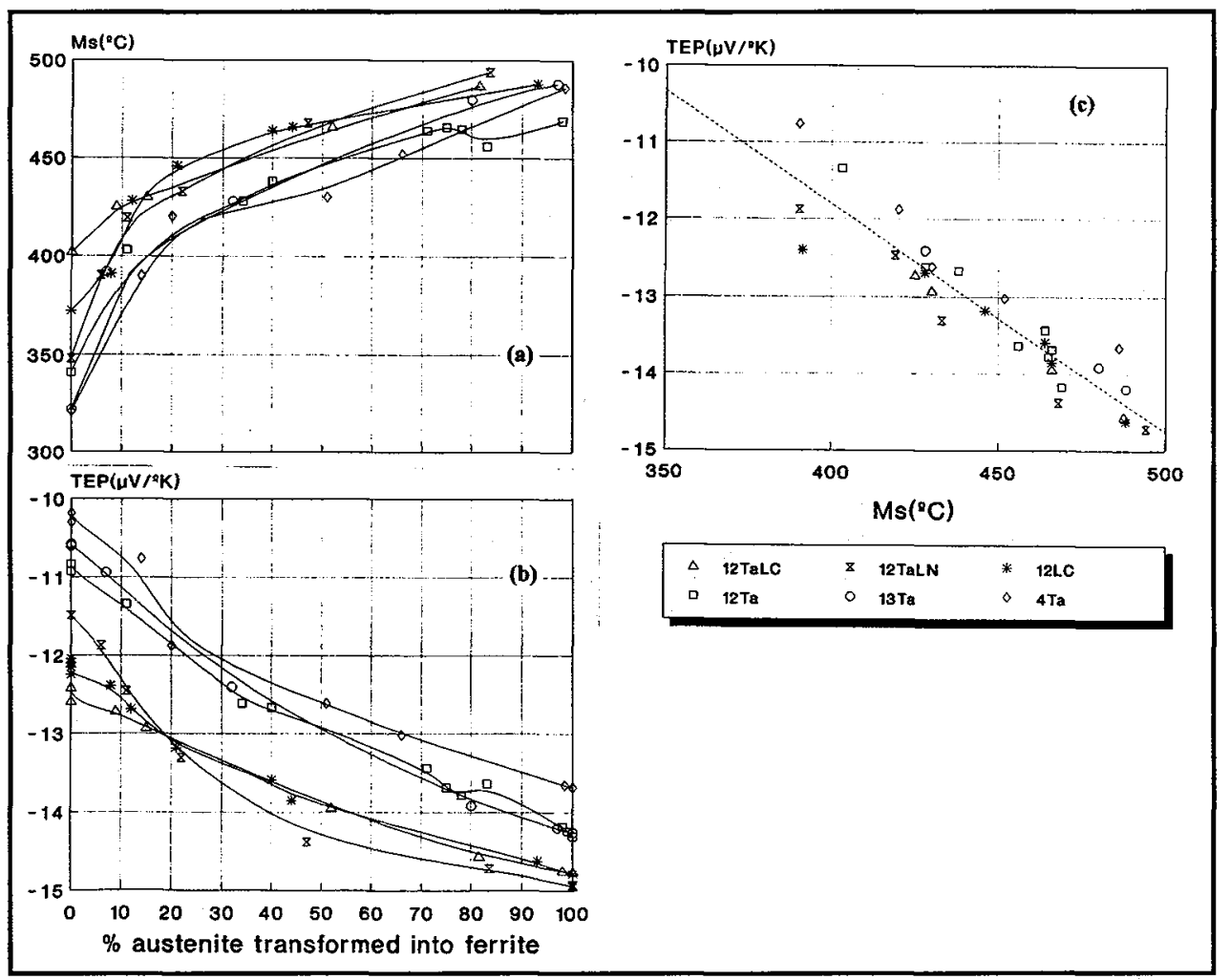

Fig. 2 : Evolution of Ms temperature and PTE experimental values as a function of the fraction of austenite transformed into ferrite during cooling

\subsection{Isothermal phase transformations :}

TTT diagrams have been established after austenitization for $30 \mathrm{~min}$. at $1050^{\circ} \mathrm{C}$ and cooling down at $400^{\circ} \mathrm{C} / \mathrm{h}$ to the $\gamma=>\alpha$ transformation temperature range $\left(600-800^{\circ} \mathrm{C}\right)$. As already observed on conventional $9 \mathrm{Cr} 1 \mathrm{Mo}$ steels [6], the TTT diagrams display a typical $\mathrm{C}$ curve; no bainitic reaction seems to occur for temperatures ranging from Ms to $600^{\circ} \mathrm{C}$, even for very long time (up to $500 \mathrm{~h}$.). The TTT "noze" temperature is closed to $700-725^{\circ} \mathrm{C}$. 
To get a better insigth of the isothermal $\gamma=>\alpha$ transformation, partial isothermal transformations have been conducted at $750^{\circ} \mathrm{C}$ (above the TTT noze) and at $650^{\circ} \mathrm{C}$ (below the TTT noze) for different fractions of austenite transformed into ferrite, ranging from 1 to $100 \%$. During the last cooling from the biphased $\gamma+\alpha$ field to the ambiant temperature, the residual austenite transforms into martensite and then the Ms temperature has been measured for each experimental thermal cycle. For the LA12TaLN steel, figure 3-a shows the evolution of the Ms temperature as a function of the fraction of austenite isothermally transformed into ferrite at both $650^{\circ} \mathrm{C}$ and $750^{\circ} \mathrm{C}$. One may notice that Ms values increase with the fraction of austenite transformed into ferrite and that the $\mathrm{Ms}$ increase is higher at $650^{\circ} \mathrm{C}$. On the other hand, TEP values decrease with the fraction of austenite transformed into ferrite (fig. 3-b). This TEP decrease is slightly faster at $650^{\circ} \mathrm{C}$ compared to $750^{\circ} \mathrm{C}$. Moreover, microhardness measurements have been performed on residual martensite grains on each $\alpha+m$ biphased samples. Figure 3-c shows that there is a decrease of the martensite hardness with increasing fraction of austenite transformed into ferrite.

\subsection{Discussion}

For both anisothermal and isothermal partial $\gamma=>\alpha$ transformations, the Ms, TEP and hardness evolutions should be related to the decrease of the interstitial $(\mathrm{C}+\mathrm{N})$ atom fraction within the solid solution of the parent austenitic phase as already discussed in [6] for conventional $9 \mathrm{Cr} 1 \mathrm{Mo}$ steel. To quantify this phenomenom, figures 4-a to 4-c plot the experimental Ms, TEP and HV values obtained after cooling at $400^{\circ} \mathrm{C} / \mathrm{h}$ from the austenitic phase as a function of the nominal $(\mathrm{C}+\mathrm{N})$ concentration. For this cooling rate, one can make the assumption that, in a first approximation, all the available $\mathrm{C}$ and $\mathrm{N}$ atoms are in solid solution within the austenite and then within the resulting martensitic structure. So, figures 4-a to 4-c seem to evidence that there is a quasi linear relation between the three experimental parameters (Ms, TEP and HV) and the concentration of interstitial atoms in the martensitic solid solution. By a linear fit we obtain respectively:

${ }^{*}$ For $\mathrm{Ms}: \quad \Delta \mathrm{Ms}=\mathrm{K}([\mathrm{C}]+[\mathrm{N}]) \quad$ where $: \mathrm{K}=-600\left({ }^{\circ} \mathrm{C} / \mathrm{wt} \%\right)$

One can remark that the fitted $K$ coefficient displays a higher value compared to the ANDREWS one $(K=423)$ [8] which has been established empirically for the effect of carbon alone on the Ms temperature value of high alloyed martensitic steels. This can be due to the supplementary contribution of nitrogen in our case.

* For microalloyed steels, values of TEP are very sensitive to the total fraction of $\mathrm{C}$ and $\mathrm{N}$ in solid solution ([2] to [5]). These authors have established a linear relation between the TEP values and the concentration of $\mathrm{C}$ or $\mathrm{N}$ in the ferritic solid solution in this class of steels. They found :

- for carbon : $\Delta \mathrm{TEP}(\mu \mathrm{V} / \mathrm{K}) \# \mathrm{~K}\{\Delta[\mathrm{C}](\mathrm{wt} . \%)\} \quad$ where $: \mathrm{K}=41+/-5 \mu \mathrm{V} /(\mathrm{K} . \mathrm{wt} . \%)$

- for nitrogen : $\Delta \mathrm{TEP}(\mu \mathrm{V} / \mathrm{K}) \# \mathrm{~K}^{\prime}\{\Delta[\mathrm{N}](\mathrm{wt} . \%)\} \quad$ where $: \mathrm{K}^{\prime}=77+/-5 \mu \mathrm{V} /(\mathrm{K} . \mathrm{wt} . \%)$

For LAM steels, we have obtained : $\operatorname{TEP}(\mu \mathrm{V} / \mathrm{K}) \# \mathrm{~K}\{[\mathrm{C}]+[\mathrm{N}]\}-14$ where : K\# $15 \mu \mathrm{V} /(\mathrm{K} . \mathrm{wt} . \%)$

* For Vickers hardness (HV5) we have obtained : $\Delta \mathrm{HV} 5$ (Vickers) \# 750. $\Delta[\mathrm{C}+\mathrm{N}]$ (in wt. \%)

We must notice that hardness is not a suitable parameter to correlate with the residual $(C+N)$ concentration in solid solution of martensite because it depends strongly on other microstructural features such as : the dislocation density, grain size, precipitation etc...

Then, from equations (1) and (4), it is interesting to estimate the evolution of the [C+N] concentration in the solid solution of non transformed austenite (and then residual martensite) as a function of the fraction of austenite transformed into ferrite. For calculations from Ms values, we can directly use the linear relation (1). But, for calculations from TEP values, we must take into account the supplementary effect on TEP increase due to the ferrite occurence. For that, one can use the experimental TEP values determined on fully ferritic samples (TEP ${ }^{\alpha}$ ) and on fully martensitic samples (TEPM). Then, for a given fraction ( $y$ ) of austenite transformed into ferrite, the TEP value must be :

$$
\mathrm{TEPy}=(1-\mathrm{y}) \cdot\left(\mathrm{TEP} \mathrm{P}^{\mathrm{M}}-15 \cdot \Delta[\mathrm{C}+\mathrm{N}]\right)+\mathrm{y} \cdot \mathrm{TEP}^{\alpha}
$$




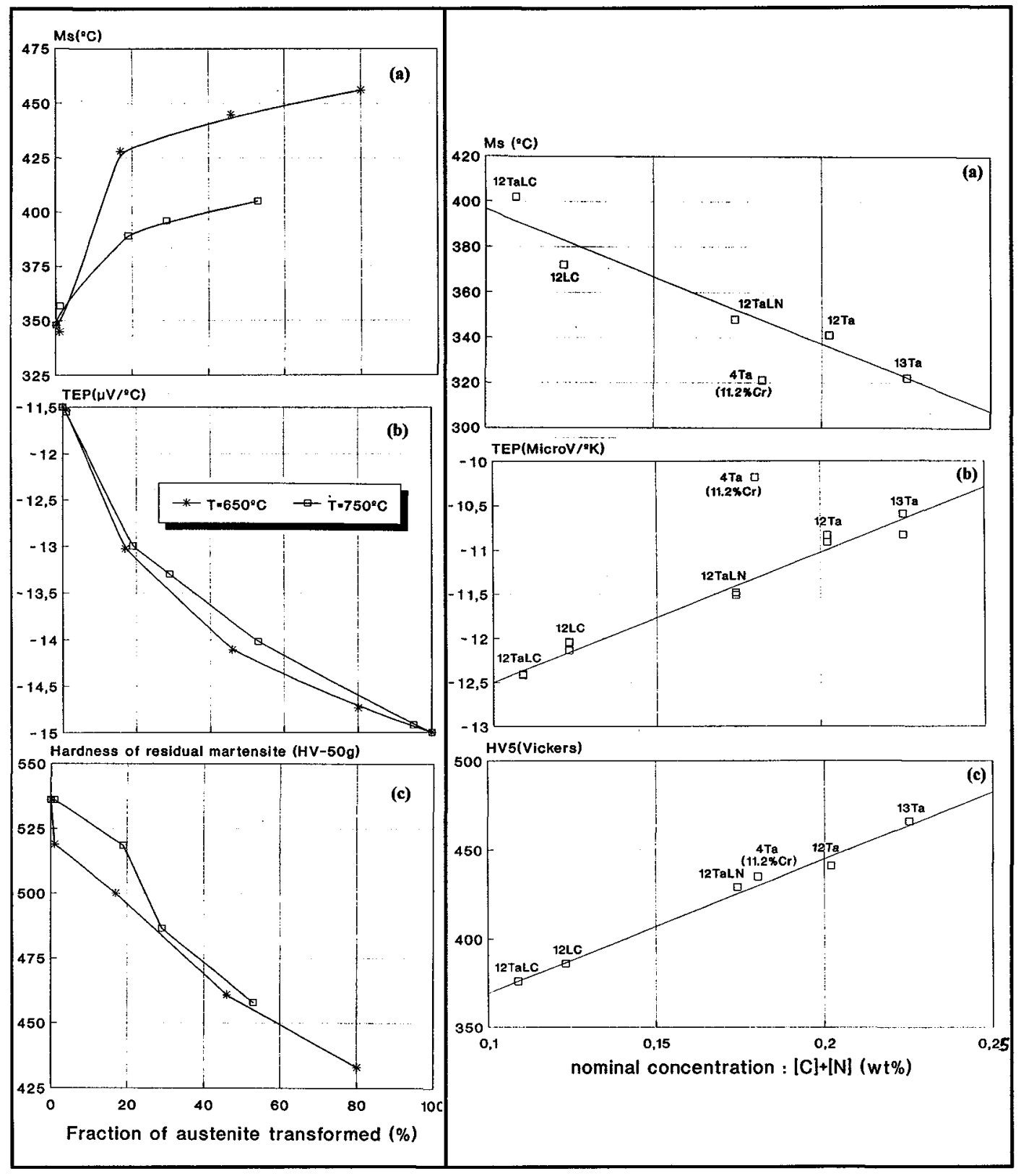

Fig. 3 : Evolution of the Ms temperature, PTE and hardness of martensite as a function of the fraction of austenite isothermally transformed into ferrite at $650 \& 750^{\circ} \mathrm{C}$.
Fig. 4 : Correlation between the nominal $\{C+N\}$ concentrations and :
(a) Ms temperatures
(b) TEP values
(c) Vickers hardness $(5 \mathrm{~kg})$

for fully martensitic samples obtained after austenitization for $30 \mathrm{~min}$. at $1050^{\circ} \mathrm{C}$ and cooling at $400^{\circ} \mathrm{C} / \mathrm{h}$. 
So, the estimated decrease of interstitial $\mathrm{C}+\mathrm{N}$ atoms concentration in the non transformed austenite is :

$$
\Delta[C+N]\left(\text { in wt.\%) }=(1 / 15) \cdot\left\{\mathrm{TEPM}^{+}(\mathrm{y} / 1-\mathrm{y}) \cdot \mathrm{TEP}^{\alpha}-\mathrm{TEP}^{\mathrm{y}} /(1-\mathrm{y})\right\}\right.
$$

Using equations (1) (with Ms experimental values) and (6-b) (with TEP experimental values), we are able to estimate the [C] concentration decrease of the non transformed austenite as a function of the transformation time at both $650^{\circ} \mathrm{C}$ and $750^{\circ} \mathrm{C}$, as shown in fig. 5 for the LA12TaLN steel.

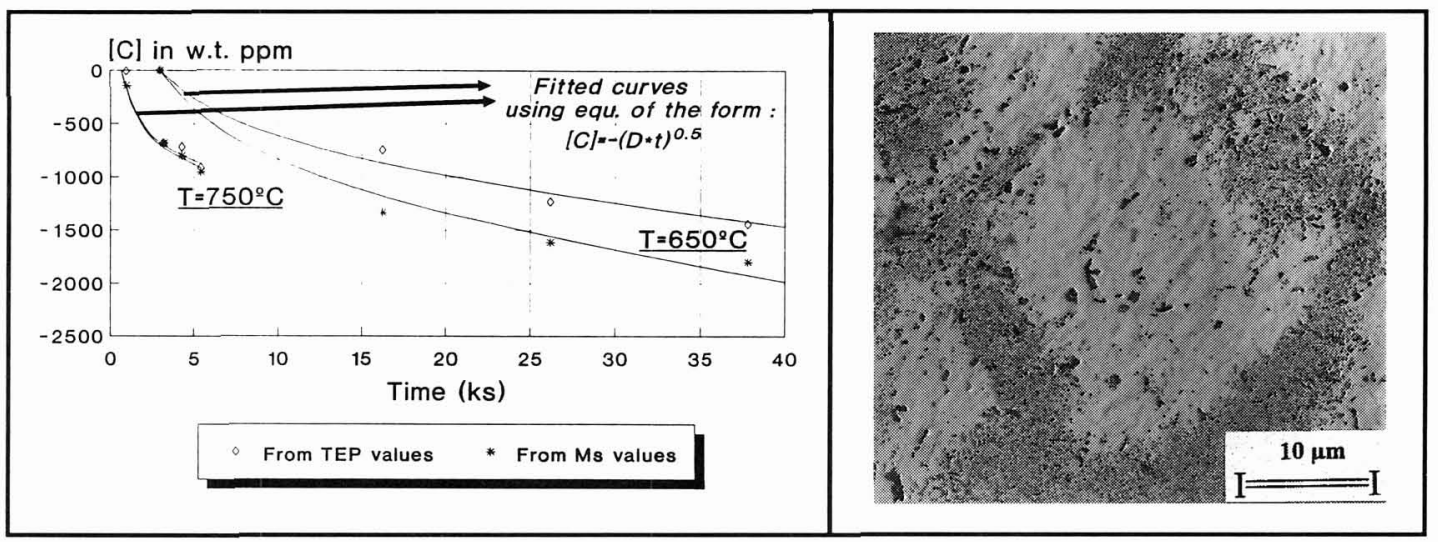

Fig. 5 : Evolution of the estimated concentration of carbon in the non transformed austenite as a function of the transformation time.
Fig. 6 : TEM micrography of a carbon replica extracted from a fully ferritic sample obtained after isothermal $\gamma=>\alpha$ transf. at $650^{\circ} \mathrm{C}$

The $[C]$ concentration evolution with the transformation time can be fitted with an equation of the form : $[C]_{t}=-(D . t)^{0.5}$. This is qualitatively in good agreement with a diffusional control mechanism for the kinetic of carbon precipitation. Thus, these results can be compared with the microstructural TEM observations performed on a carbon replica extracted from a sample isothermally transformed at $650^{\circ} \mathrm{C}$ (below the TTT "noze") as shown on fig. 6. All the chromium rich carbides are located near the prior austenitic grain boundaries indicating that the precipitation reaction has occured very early during the isothermal ferrite growth. Some complementary thermodynamical calculations [9] have been made using "MTDATA" software associated with the SGTE data-base for steels. These calculations seem to confirm the proposed mechanism. The equilibrium solubility of carbon in austenite decreases drastically for temperatures below $700^{\circ} \mathrm{C}$. As a consequence and because of the high diffusivity of interstitial C (and N) atoms in the austenite (compared to the growth kinetic of alliotromorphic ferrite which is controled by the substitutional $\mathrm{Cr}$ and/or W atoms diffusion [6]), the very low solubility limit of carbon in austenite (quite the same value for ferrite) is achieved early during the $\gamma=>\alpha$ transformation due to the early precipitation of carbides.

By way of conclusion, one may notice that Ms measurements by dilatometry and TEP values are very convenient experimental parameters to quantify the $[\mathrm{C}+\mathrm{N}]$ interstitial atoms concentration within the solid solution of martensite for this class of steels. Further experiments will be necessary to deconvoluate the separate effects of $\mathrm{C}$ and $\mathrm{N}$ on these both parameters.

\section{REFERENCES}

[1] Abe F., Noda T., Okada M., JNM 195 (1992), 51-67.

[2] Borelly R. et al., Acta Met., Vol. 33, No 5, (1985), 855-866.

[3] Benkirat D. et al., Acta Met., Vol. 36, No 3, (1988), 613-620.

[4] Biron I. et al., Mém. et Et. Scientif. - Rev, de Métallurgie, (Nov. 1991), 725-733.

[5] Borelly R, al., La Revue de Métallurgie-CIT/Science et Génie des Mat., (May 1993), 685-695.

[6] Brachet J.C., Journ. de Phys. IV, Colloque C3, suppl. au Journ. de Phys. III, Vol. 4, (Feb. 1994).

[7] Brachet J.C. et al., "Physical metall. and mech. prop. of $9 \mathrm{Cr} 1 \mathrm{Mo}(\mathrm{Nb}, \mathrm{V})$ steels", to be published in Mat. Science and Tech.

[8] Kung C. Y. et al., Met. Trans., Vol. 13A, (Feb. 1982), 328.

[9] Gavard L. and Badeshia H.K.D.H.,Mat. Sci. Dep., Cambridge University, Unpublished data, (1995). 